Discourse and Communication for Sustainable Education, vol. 8, no. 1, pp. 53-63, 2017

\title{
Seeking Refuge: \\ Implications when Integrating Refugee and Asylum Seeker Students into a Mainstream Australian School
}

\author{
Martin Wiseman and Shannon O'Gorman \\ St James College, Brisbane, Australia
}

\begin{abstract}
This article describes one school's response to the inclusion and education of refugee and asylum seeker students within a mainstream educational setting. Australian government statistics released on 31 March 2016 stated that there were presently 50 children being held on Nauru, 17 children held in detention on the mainland and 317 children held in community detention on the mainland (ChilOut, 2016). Refugee and asylum seeking students are subject to the impact of war and conflict; the cumulative time spent in detention may severely limit a young person's access to formal education. Whilst it is understood that children will benefit from access to education, the reality is that "little appears to have been written on asylum seekers" in an educational context (Reakes, 2007, p. 94). This represents a concern when it is acknowledged that "sustaining teachers in culturally and linguistically diverse schools has been a prominent issue for years" (Williams, Edwards, Kuhel, \& Lim, 2016, p. 17). This article responds to the limitations of current literature by articulating considerations that would likely assist other schools seeking to establish similar inclusive frameworks. Specifically, the thematic grouping of staff observations seek to articulate the cultural considerations that likely influence the sustainability of an inclusive and liberating approach to integrative school enrolment. This paper draws on the authors' observations and experiences in schools, the published literature and the observations of the two authors - specifically, drawing on their educational and therapeutic expertise. These observations are then grouped into themes outlined by Akinsulure-Smith and O'Hara (2012) as key reasons for therapeutic referral, namely: employment barriers, medical challenges, language barriers, social services and legal challenges.
\end{abstract}

Keywords: refugee, asylum seeker, pastoral care, asylum seeker students. 


\section{Challenges to Sustaining the Inclusivity of New Arrivals}

The integration of students from a refugee or asylum seeker background within a mainstream school is necessarily fraught with complexity. According to Cassity and Gow (2005), "Schools are endowed with the task of transforming these young people into national citizens and coordinating their cultural identities" (p. 52). It has been suggested that education is prized amongst refugee cohorts who are alert to "...the high stakes they had in making sure that school worked for them" (Uptin, Wright, \& Harwood, 2013, p. 128). The advantages afforded by education extending to include "...the improvement of physical and mental well-being for children and adolescents, including refugee children” (Mace, Mulheron, Jones, \& Cherian, 2014, p. 985). However, the educational experience is necessarily complicated by "a range of needs and experiences for which existing [educational] procedures were not always appropriate." (Reakes, 2007, p. 105). The practicalities of integrating asylum seeker and refugee young people into mainstream schooling is likely challenged by concerns such as minimal knowledge relating to how schools are able to best support young people and the challenges associated with integration within a predominantly 'Australian' cohort of students (Uptin, Wright, \& Harwood, 2013, p. 126-130). Hence the need for individual schools and the educational system as a whole to consider sustainable programs that foster individual growth whilst also ensuring connections between individuals (de Souza, 2016, p. 131).

It has been suggested that "Australia has one of the harshest regimes for the processing of asylum seekers" (Zion, Briskman, \& Loff, 2012, p. 67). Mandatory detention was introduced in Australia in the year 1992 by then Prime Minister, Paul Keating. This policy requires that nationals from other countries without a visa be held until granted a bridging or alternative visa (Philips \& Spinks, 2013). This process can take months or even years. Some will argue that this approach - specifically transfers to the offshore immigration detention centres of Manus and Nauru - represents a direct response to deaths at sea - a legitimate concern given that 15 children were estimated to die at sea between 2008 and 2013 alone (Australian Human Rights Commission, 2014a). Yet, the reality exists that in July of 2013 some 1,992 children were being detained (Australian Human Rights Commission, 2014a).

In 2014 the United Nations Committee Against Torture was observed to have:

...formally recorded its serious concerns about the transfer of asylum seekers to Nauru and Manus. The committee noted that the combination of harsh conditions, protracted periods of closed detention and uncertainty about the future was reported to have created 'serious physical and mental pain and suffering' and urged Australia to take all necessary measures to guarantee that asylum seekers were protected against torture and cruel, inhuman or degrading treatment, regardless of when or how they had arrived. (Gleeson, 2016, p. 264).

It has been suggested that mandatory detention risks eroding initial resilience and has an adverse effect upon health and well-being (Mace, Mulheron, Jones, \& Cherian, 2014, p. 991). Not only do the conditions of the detention facility likely contribute to mental health concerns, but detention facilities are ill-equipped with treatment options (Zion, Briskman, \& Loff, 2012, p. 70). 
Furthermore, there exist specific concerns about detaining young people in formal detention. For example, Consultant Paediatricians Elliott and Gunasekera (2015) recommended that no child be held in Nauru nor any formal detention centre. Gleeson (2016) provides specific and repeated descriptions of "sexual, physical and emotional abuse of children in the Nauru RPC” (p. 312-314). Yet, at least 67 children still appear to reside in such facilities. Though educational opportunities are reported to exist in formal detention, questions have been raised as to whether the services provided are comparable with those in the community (Australian Human Rights Commission, 2014b).

\section{Participants - Inclusivity of Refugee and Asylum Seeking Students}

The Government policies that determine the processing and treatment of young people arriving without relevant visas, coupled with the commitment of this school towards providing a liberating and inclusive educational experience have provided the conditions for which students from asylum seeker and refugee backgrounds have enrolled in this specific school in significant numbers. Over time, the countries of origin have shifted from those leaving the African continent, to a greater influx of students from the Middle East. At the time of publication, in excess of 40 different cultural backgrounds were represented amongst student enrolment

This article has been informed by the observations of an Assistant Principal (Pastoral) and Counsellor working in a Catholic school located in Brisbane, Australia. According to Laine:

Pursuing a sustainable way of living is about broadening the whole educational system's way of thinking about new school culture. Without acknowledging the cultural perspective, the pursuit of sustainability fails (2016, p. 65).

Attending to the culture of this specific school, it is meaningful to note that this is a Catholic high school that deliberately strives towards “... a liberating education, based on a gospel spirituality, within an inclusive community committed to justice and solidarity." (Edmund Rice Education Australia, 2016). As such, inclusion of vulnerable and minority cohorts such as refugee and asylum seeking students is strongly supported.

Refugee and asylum seeking students represent distinct entities in and of themselves. An asylum seeker is understood to be someone who has fled their country due to fear of persecution but has not yet had their claim assessed. The practical application within Australia being that such a person has limited security with reference to length of stay and reduced educational options. In contrast, a refugee is understood to be someone who has fled their country due to fear of persecution and has not only had their claim assessed - a process that can take years - but has also has been found to have their circumstances verified. The ramifications are many but include permanency, and significantly greater exposure to affordable tertiary education. Acknowledging the differences between these two groups, it also bears highlighting that defining any individual as belonging to either grouping represents a gross simplification that risks ignoring an “individual's needs and strengths” (Uptin, Wright, \& Harwood, 2013, p. 135). The injustice of such a simplification is even more apparent when it is acknowledged that in many cases "components of identity are the very factors that led to the client's forced migration” (Akinsulure-Smith \& O’Hara, 2012, p. 47). 


\section{Design - Theoretical Grouping of Referrals}

Akinsulure-Smith and O'Hara (2012) have described therapeutic considerations relevant to working with this cohort. In particular, they identified five key areas for referral, namely: employment barriers, medical challenges, language barriers, social services and legal challenges. These five domains offer a framework for describing the implications for a mainstream school seeking to offer an inclusive education to this cohort. These domains will now be used to group the observations of two staff members along theoretical lines.

\section{Methodology - Themes Arising}

\section{Employment: Educational Barriers}

The influence of cultural requirements, war/conflict, resulting period of transit towards presumed safety and culminating time spent in detention may severely limit a young person's access to formal education - meaning that some students may in fact be well into their adult years (Reakes, 2007, p. 97). This theme of disruption may continue to be reflected in their new school context whereby few likely start at the beginning of term (Strauss \& Smedley, 2009, p. 4). Inconsistencies between a student's age and their educational level have been reported elsewhere (Cassity \& Gow 2005; Uptin, Wright, \& Harwood, 2013). Such inconsistencies may arise as a result of multiple factors, not least: inability to access documentation/ loss of documentation in transit; long transit times with increased likelihood of incorrect documentation (Mace, Mulheron, Jones, \& Cherian, 2014, p. 990). As such, whether the mainstream school is aware or not, they may well have enrolled students past the traditional age of 18 years.

Ordinarily, Queensland state law would call for adults above the age of 18 to enrol in a mature aged state school (Queensland Government, 2015). Furthermore, in an attempt to "create safe and supportive environments for children and young people when receiving services and participating in activities which are essential to their development and wellbeing, such as child care, education, sports and cultural activities" staff, inclusive of volunteers and trainee students, must hold a blue card if coming into contact with young people (Queensland Government, 2016). No such requirement exists when the asylum seeker is placed as a student within a mainstream school. As such, schools are cautioned to remain conscious that any adult - even a student of mature age - must recognise the vulnerabilities of minors and ensure appropriate sexual boundaries and legal responsibilities are maintained.

\section{Medical: Trauma}

Asylum seeking and refugee students will, by definition, present with claims of having been subject to persecution. These students frequently describe the grief associated with leaving behind family and friends, coupled with the burden associated with the responsibility associated with finding asylum themselves and then attempting to find passage for the rest of their family. Regardless of the legitimacy of any claim for refugee status, Australia's commitment to mandatory detention undoubtedly cements exposure to traumatic events. In 2014, the Australian Human Rights Commission found that 
"...the mandatory and prolonged immigration detention of children is in clear violation of the Convention on the Rights of the Child" (2014b). The physical environment having been described as "...tents - infested with insects and rats - offered little privacy or room to move between the camp stretchers that served as beds" (Gleeson, 2016, p. 32). As such, even common school experiences have potential to cause a flooding of previous memories. For example, a teacher's attempt to regain control of a noisy classroom by using abrupt demands may inadvertently resemble the authoritative position taken by guards in the detention centre. The conditions on a school camp may mirror aspects of those experiences associated with communal living in minimal housing conditions, exposure to the extremes of weather and the significant lack of control over one's physical placement and consequent human interactions associated with these detention settings. Recognising the capacity for current circumstances to augment the distress caused by historical events, careers counselling and post-school transition planning needs to be managed with extreme tact given that asylum seekers on bridging visas are at times prohibited from applying for employment or engaging in further study after the completion of grade 12 .

When supporting young people from an asylum seeker background, there is a need to recognise that this is a population who have been observed to express their distress through somatic symptoms (Mace, Mulheron, Jones, \& Cherian, 2014; Mann \& Fazil, 2006, p. 59). The Diagnostic and Statistical Manual of Mental Disorders, $5^{\text {th }}$ edition describes Somatic Symptom Disorder as typically having “...multiple, current, somatic symptoms that are distressing or result in significant disruption of daily life" (American Psychiatric Association, 2013, p. 311). It is recognised that somatic symptoms are more likely to present in cases of early trauma and "...cultural/social norms that devalue and stigmatize psychological suffering as compared with physical suffering." (American Psychiatric Association, 2013, p. 310).

Challenging the notion that symptoms are problematic can feel counterintuitive. Yet, when an individual present with repetitive physical ailments or heightened symptoms, staff are challenged to make sense of the somatic symptom in a manner that neither dismisses the individual's reality nor ignores its possible meaning. Questions must be asked as to whether a particular symptom aids or impairs the student's overall level of function. For example, physical symptoms may in fact serve as a useful means of help seeking, or engaging others in a discussion about personal distress. As such, a desirable response might include validating that the student's experience of the physical symptom is likely very real, even if it's meaning might be worthy of further exploration.

Another common observation is that of hyper vigilance - a feature of Post-Traumatic Stress Disorder - that involves an over arousal of the senses. Whilst this symptom may be conceptualised as part of a psychiatric diagnosis, simultaneously, it will be important to recognise that until recently hyper vigilance may well have been a protective factor for the individual and essentially, reflects that the individual's coping mechanisms have changed as quickly as have their physical surroundings. Anxiety Disorders are typically characterised by 'excessive' worry - the subjectivity of this term is apparent when known trauma or unknown history of a student is taken into account. As such, there may be call to explicitly acknowledge that current, repetitive and ongoing anticipation of distress may represent a psychological response to a history steeped in excess exposure to danger or stressors and as such, might benefit from professional intervention. 


\section{Language: Receptive and Expressive Skills}

Though "prolonged, mandatory detention of asylum seeker children causes them significant mental and physical illness and developmental delays" (Australian Human Rights Commission, 2014b), it is recognised that this same population is unlikely to accept mental health services on account of “...stigma, financial constraints, fear of missing school, language barriers and the low priority of mental and developmental health compared with other physical issues." (Mace, Mulheron, Jones, \& Cherian, 2014, p. 990). Even if a young person does engage with specific mental health services, there is a need to reflect upon the appropriateness of assessments done in English. For example, when assessing a person's risk of self-harm or suicidal ideation, questions should be asked about perceived safety and identifiable risks. A young person may be able to 'guarantee their safety' as they relate the term 'safety' to mean no perceived imminent risk within their environment. As such, this phrase is unlikely to have the usual applicability to mean that the child is able to contract that they won't harm themselves. Recognising the value associated with employing therapeutic staff and engaging with culturally sensitive agencies experienced in supporting survivors of trauma, the challenges engaging this cohort within traditional mental health contexts requires schools to recognise that it is the interactions of all staff that are likely to create meaningful change.

Students of refugee and asylum seeker background are likely to require specialist English lessons. Whilst the term ESL or English as a Second Language is applied, the reality for these students is that English may be a third, fourth or even fifth language. This reflects the thousands of languages spoken in Africa, influence of Arabic within Islam, and those languages acquired in transit (e.g. Indonesian). In addition to the obvious language difficulties associated with not having English as a first language, many students have also had a significantly interrupted education in their country of origin. This can be due to many factors including war and conflict, ethnic marginalisation and gendered limitations. Regardless of the cause, students may have limited capacity to interpret or receive - written documents from their country of origin. In the event that the parent/ s of the student have travelled with the student, the capacity of the parent to support the emotional well-being of the student may be limited on account of the influence of their own lived experience and traumas upon their own emotional well-being (Strauss \& Smedley, 2009, p. 4). As such, schools may be required to call upon the services of an interpreter in order to assist a student to receive or express information. This is likely a costly service that is linked directly to a cohort for whom there may be no government funding on account of the student's mature age. As such, other students fluent in English and the native dialect may, by necessity, be utilised, assuming the permission of all parties.

\section{Social Services: Independent Students}

The term 'unaccompanied minor' is “a broad term used to describe a non-citizen, under 18 years of age who does not have a parent to care for them in Australia” (Australian Human Rights Commission, 2014). In observing these students, it has been noted that many face the challenge of searching for accommodation despite limited financial means, often balancing competing schedules of school attendance and house inspections. They are tasked with developing an instant capacity to negotiate medical and immigration 
systems in a country whose systems are foreign to them and using a language that they have only recently begun to acquire. As young adults, they must forsake the common adolescent processes of separation, differentiation and individuation from parents in favour of expensive, time-sensitive attempts to connect with family members back home using the electronic means within their financial reach. The contrast between the highly structured, rule bound school environment and the autonomy of their own lives could not be much greater. By day these are students who might engage with a teacher in order to proof read an assignment, by evening they are solely responsible for all aspects of their wellbeing. It is not uncommon for these students to articulate that it can be challenging to remind themselves of the value placed upon attendance, assessment and uniform when their thoughts so often turn to the different realities that exist in the country of origin and for people left behind.

Therapeutically, the chasm between the individual as student versus individual living independently presents during moments of crisis - often threats of self-harm or suicidal ideation - in which the usual attempts to engage a family member as part of a least restrictive safety plan no longer represents an option. For such children, their guardian:

...falls to the immigration minister, the same person responsible for implementing the government's policy of sending offshore everyone arriving by boat, without exception. Advocates and medical professionals have argued that this dual role creates an irreconcilable conflict of interest for the minister (Gleeson, 2016, p. 125).

Clearly, the capacity of a formalised guardianship arrangement such as this is not only ethically questionable but leaves an already vulnerable young person without any secure base, or attachment figure. Once a minor turns 18 , they are no longer allocated any guardian. The reality being that a school employee - be that teacher or counsellor may well represent the first point of contact in relation to a medical, housing or mental health concern.

\section{Legal: Child Protection and Restrictions}

The conditions associated with mandatory detention have been recognised to place children at risk of being victims of abuse. Specifically, it was understood that children were not infrequently exposed to violence and self-harm (Gleeson, 2016, p. 318; Zion, Briskman, \& Loff, 2012, p. 69). Yet, those workers employed on Nauru to protect these children have not always been screened in line with standards established on the mainland. For example,

There was no way to perform 'working with children' checks for Nauruan employees, meaning they were recruited to work in close contact with children after simply answering a few 'behavioural questions', signing a statutory declaration and agreeing to a code of conduct. (Gleeson, 2016, p. 331).

Furthermore, even if a risk to the young person was identified, the likelihood of an appropriate response has been called into question. Specifically, "Psychiatrists were asked by the child protection system to make assessments of the health of children in Woomera and Baxter, knowing full well that their reports would not be acted upon." 
(Zion, Briskman, \& Loff, 2012, p. 72). In the school setting, staff may be hesitant to report child protection concerns that are unlikely to meet criteria for concern but are almost certain to bring the family increased scrutiny from an immigration system that is not known for transparency.

Further, those students living in community detention are often subject to curfews, denied work rights, and may face limitations in providers of health care (Asylum Seeker Resource Centre, 2013). On a practical level this means that students report that they require written permission from the Department of Immigration in order to attend school events that might finish after their 10 pm curfew - school camps, performances, and social events being obvious examples.

\section{Discussion}

Government policies, combined with a commitment to providing young people with a liberating and inclusive education have created the ideal conditions for enrolment of large numbers of refugee and asylum seeking students within a mainstream school, located in Brisbane Australia. In recent times Akinsulure-Smith and O'Hara (2012) have identified five domains that demand therapeutic consideration. These categories have been applied throughout this article to structure the thematic description of some of the challenges facing this cohort as a whole and the pastoral considerations within a mainstream school context. Specifically, these categories highlight concerns relating to student age (employment/education), independent living status (social services), previous trauma history (medical), expressive and receptive communication (language skills) and exposure to past illegal treatment and ongoing restrictions (legal). For the purpose of this article, the pragmatics detailing the specifics of how to respond to refugee and asylum seeking students have been forsaken in favour of articulating meaningful theoretical considerations for schools seeking to open their doors to new arrivals - thus supporting the position that sustainability should be inherent in "a vision and values central of the policy of the school" (Iliško \& Badjanova, 2014, p. 46). However, the following considerations represent examples of key pragmatic considerations that demand attention when working with this population.

The enrolment of students from asylum seeker and refugee minority backgrounds in a mainstream school necessitates a range of staffing implications. From the outset schools are challenged to ensure equity of information is provided. Examples of adaptations include translation of prospectus/enrolment forms and automated translation services on websites. Leadership staff may ensure that all staff are alerted in advance of the arrival of a new student -including specifics such as country of origin, literacy in their first language, English proficiency, previous educational level, exposure to or time spent in refugee camps (Strauss \& Smedley, 2009).

The availability of English as Second Language teachers is critical to the support of these students across all subject areas. In terms of academic content, these are students for whom the regular English curriculum will need be adapted through offerings such as English Communication and English as a Second Language. A more holistic response would focus not only on academic content, but also the processes that enable learning. Indeed, the role of the ESL teacher might be augmented to accommodate the recommendation that schools seek to support these students by employing staff member who has special responsibility for refugees (Strauss \& Smedley, 2009). The demands on this 
role would demand an awareness of the cultural and political sensitivities that accompany new arrivals seeking freedom from persecution. Key support staff may require access to guidance (professional supervision) and support (debriefing) such that their skill sets can be augmented. Further, the recommendations applied by Williams, Edwards, Kuhel and Lim (2016) pertaining to the teaching of STEM to culturally and linguistically diverse populations offer additional points of consideration, namely "Monthly seminars and professional conferences focused on cultural responsiveness, teaching for social justice." (p. 27).

Careers and guidance counsellors will necessarily need to increase their exposure to the implications of different visas and associated work and study restrictions. Barriers to employment are many and include restrictions on seeking employment, the challenge of compiling a resume when evidence of identity or past training is minimal or nonexistent and significantly increased tertiary fees. In the course of discussing possible post-school pathways, the counsellor is likely to become alert to any number of challenges that restrict the student's capacity to attend and engage at school or seek employment. Examples being a lack of stable housing or scheduling meetings with legal representation during school hours. In such instances close and regular contact with external government and non-government organisations is likely to assist the counsellor to ensure the boundary around school based concerns is maintained, whilst the immediate needs of the student likely to restrict education if unmet - are addressed. Respecting the limited financial means that originates out of unemployment or underemployment, lack of familiarity that accompanies a move to a new city, and distrust that can originate when first experiences of the Australia are as described earlier in piece, it is proposed that professionals from existing external culturally-specific services may be supported to attend on site.

In terms of Pastoral Care structures in the school that support these students, the College embraces a vertical Pastoral system organized into four Houses. Within these House groupings there are five Homerooms which contain approximately twenty-five students varying in ages from eleven to students in their early twenties. The intention of this structure is to encourage interactions in the Homeroom where older students care for the younger ones according the philosophy of the College outlined in the Touchstones listed above. This structure is also supportive of students from asylum seeker backgrounds as Australian students are charged with leading the Homeroom and caring for all the students therein. Additionally, the reactive behaviour management processes which are based around the principles of Restorative Justice also serve to honour the stories of these students in such a way that any consequences given from their behavioural choices are mitigated by their experiences.

\section{Conclusions}

Just as paediatrician and psychoanalyst Donald Winnicott's description of the 'goodenough mother' makes space for the importance of 'failure', it is proposed that a school cannot and should not seek to be all things to these vulnerable students. The needs of this cohort are often many and varied - often sitting outside the usual expertise and practice of mainstream school staff. For example, a student might reveal a medical illness, yet have no previous interaction with accessing the medical system. Conversely, a student may phone in absent for school on the basis of needing to engage with the court system, yet have no knowledge of the possibility that they might be eligible for 
representation. In such instances school staff are presented with the dilemma that whilst they may well represent one of a small sample of supports available to the student, their professional and personal resources are already allocated elsewhere.

Rather, the task for the school is to provide a corrective emotional experience such that the student has developed their own resilience - ready to face a world in which access to further study or even work may be prohibited due to visa conditions. As such, the onus must be on the teaching of meta-level skills - such that the student is more skilled and experienced in problem solving future challenges for themselves. Though this article discusses content of a pastoral nature, it will frequently be the academic process that scaffolds the student's daily experiences. These are students for whom an inclusive, cooperative approach will in itself represent news of a difference. Thus reflecting the position that sustainability requires schools to embrace a systemic conceptualisation of how all the initiatives fit together in a more holistic frame (Salite, 2015).

\section{References}

Akinsulure-Smith, A. \& O'Hara, M. (2012). Working with forced migrants: Therapeutic issues and considerations for mental health counsellors. Journal of Mental Health Counselling, 34(1), 38-55.

American Psychiatric Association. (2013). Diagnostic and statistical manual of mental disorders: Fifth edition. Washington: American Psychiatric Publishing.

Asylum Seeker Resource Centre. (2013). Community based asylum seekers. Retrieved from http://www.asrc.org.au/wp-content/uploads/2013/07/Community-BasedAsylum-Seekers_August-20132.pdf

Australian Human Rights Commission. (2014a). The forgotten children: National inquiry into children in immigration detention. Retrieved from https://www.humanrights. gov.au/sites/default/files/document/publication/forgotten_children_2014.pdf

Australian Human Rights Commission. (2014b). The forgotten children: National inquiry into children in immigration detention 2014 summary factsheet. Retrieved from https:/www.humanrights.gov.au/publications/last-resort-national-inquiry-childrenimmigration-detention/12-education-children

Cassity, E., \& Gow, G. (2005). Making up for lost time: The experiences of Southern Sudanese young refugees in high school. Youth Studies Australia, 24(3), 51-55.

Children Out of Immigration Detention. (2016). Children in immigration detention. Retrieved from http://www.chilout.org/

De Suoza, M. (2016). The spiritual dimensions of education in addressing issues of identity and belonging. Discourse and Communication for Sustainable Education, $7(1), 125-128$.

Edmund Rice Education Australia. (2011). Edmund Rice Education Australia: About EREA. Retrieved from http://www.erea.edu.au/about-us/about-erea

Elliott, E., \& Gunasekera, H. (2015). The health and wellbeing of children in immigration detention: Report to the Australian Human Rights Commission monitoring visit to Wickham Point Detention Centre, Darwin, NT.

Iliško, Dz., \& Badjanova, J. (2014). A case study of ESD implementation: Signs of sustainable leadership. Discourse and Communication for Sustainable Education, 5, 38-48. 
Lain, M. (2016). Culture in sustainability - defining cultural sustainability in education. Discourse and Communication for Sustainable Education, 7(2), 52-67.

Mace, A.O., Mulheron, S., Jones, C., \& Cherian, S. (2014). Educational, developmental and psychological outcomes of resettled refugee children in Western Australia: A review of school of special educational needs: Medical and mental health input. Journal of Paediatrics and Child Health, 50, 985-992.

Mann, C., \& Fazil, Q. (2006). Mental illness in asylum seekers and refugees. Primary Care Mental Health, 4, 57-66.

Marsh, K. (2016). 'The beat will make you be courage:' The role of a secondary school music program in supporting young refugees and newly arrived immigrants in Australia. Research Studies in Music Education, 34(2), 93-111.

Phillips, J., \& Spinks, H. (2013). Immigration detention in Australia. Retrieved from 2016.http://parlinfo.aph.gov.au/parlInfo/download/library/prspub/1311498/ upload_binary/1311498.pdf;fileType=application/pdf

Queensland Government. (2015). Enrolment age requirements. Retrieved from https://www.qld.gov.au/education/schools/find/enrolment/pages/age.html

Queensland Government. (2016). The blue card system. Retrieved from https://www. bluecard.qld.gov.au/

Reakes, A. (2007). The education of asylum seekers: Some UK case studies. Research in Education, 77, 92-107.

Salìte, I. (2015). Searching for sustainability in teacher education and educational research: Experiences from the Baltic and Black Sea Circle Consortium for educational research. Discourse and Communication for Sustainable Education, 6, 21-29.

St James College. (2016). St James College: About us. Retrieved from http://www.stjames college.qld.edu.au/about-us/st-james-college/erea/

Strauss, P., \& Smedley, F. (2009). Welcoming refugees into New Zealand schools. New Zealand Journal of Educational Studies, 44(2), 3-18.

Uptin, J., Wright, J., \& Harwood, V. (2013). 'It felt like I was a black dot on white paper': Examining young former refugees' experience of entering Australian high schools. Australian Education Research, 40, 125-137.

Williams, D.L., Edwards, B., Kuhel, K.A., \& Lim, W. (2016). Culturally responsive dispositions in prospective maths teachers. Discourse and Communication for Sustainable Education, 7(2), 17-33.

Zion, D., Briskman, L., \& Loff, B. (2012). Psychiatric ethics and a politics of compassion. Bioethical Inquiry, 9, 67-75.

Correspondence concerning this article should be addressed to Mr Martin Wiseman, Assistant Principal Pastoral, St James College, 201 Boundary Road, Brisbane, Queensland, Australia. Email: Martin.Wiseman@stjamescollege.qld.edu.au 